\title{
The relationship between serum uric acid and cognitive function in patients with chronic heart failure
}

\author{
Weihua Niur ${ }^{1,2 \dagger}$, Huifeng Yang ${ }^{3 \dagger}$ and Chengzhi Lu ${ }^{2^{*}}$ (D)
}

\begin{abstract}
Background: Evidence has shown that serum uric acid (UA) is associated with cognitive function, but this finding remains debatable. Serum UA is commonly elevated in patients with chronic heart failure (CHF), especially in men. However, the relationship between serum UA and cognitive function in CHF populations and stratified by sex are unclear. We aimed to examine whether serum UA was independently associated with cognitive function in CHF populations after controlling for demographic, medical and psychological variables and whether there was a sex difference in the association between serum UA and cognitive function among male and female CHF patients.

Methods: One hundred ninety-two hospitalized patients with CHF underwent an assessment of cognitive function using the Montreal Cognitive Assessment (MoCA) and the determination of serum UA. Hyperuricemia was defined as serum $U A \geq 7 \mathrm{mg} / \mathrm{dl}$ in men and $\geq 6 \mathrm{mg} / \mathrm{dl}$ in women. Multiple linear hierarchical regression analyses were conducted to examine the independent association between serum UA and cognitive function in CHF populations and stratified by sex.
\end{abstract}

Results: The mean serum UA concentration of participants was $7.3 \pm 2.6 \mathrm{mg} / \mathrm{dL}$. The prevalence of hyperuricemia was 54.7\% (105 of 192) in CHF patients, 52.9\% (64 of 121) in men, and 57.7\% (41 of 71) in women. In the total sample, higher serum UA was associated with poorer cognitive function independent of demographic, medical and psychological variables $\left(\beta=-0.130, \Delta R^{2}=0.014, p=0.015\right.$ ). In sex-stratified groups, elevated serum UA was independently associated with worse cognitive function in men $\left(\beta=-0.247, \Delta R^{2}=0.049, p=0.001\right.$ ) but not in women $\left(\beta=-0.005, \Delta R^{2}=0.000, p=0.955\right)$.

Conclusions: Higher serum UA is independently associated with poorer cognitive function in CHF populations after adjusting for confounding variables. Furthermore, elevated serum UA is independently related to worse performance on cognitive function in men but not in women. More longitudinal studies are needed to examine the association between serum UA and cognitive function in CHF populations and stratified by sex.

Keywords: Cognitive impairment, Heart failure, Serum uric acid

\footnotetext{
*Correspondence: lucz8@126.com

${ }^{\dagger}$ Weihua Niu and Huifeng Yang contributed equally to this work.

${ }^{2}$ Department of Cardiology, Tianjin First Central Hospital, No 24 Fukang Road, Nankai District, Tianjin 300192, China

Full list of author information is available at the end of the article
}

(c) The Author(s). 2020 Open Access This article is licensed under a Creative Commons Attribution 4.0 International License, which permits use, sharing, adaptation, distribution and reproduction in any medium or format, as long as you give appropriate credit to the original author(s) and the source, provide a link to the Creative Commons licence, and indicate if changes were made. The images or other third party material in this article are included in the article's Creative Commons licence, unless indicated otherwise in a credit line to the material. If material is not included in the article's Creative Commons licence and your intended use is not permitted by statutory regulation or exceeds the permitted use, you will need to obtain permission directly from the copyright holder. To view a copy of this licence, visit http://creativecommons.org/licenses/by/4.0/ The Creative Commons Public Domain Dedication waiver (http://creativecommons.org/publicdomain/zero/1.0/) applies to the data made available in this article, unless otherwise stated in a credit line to the data. 


\section{Background}

Chronic heart failure (CHF) is a significant health problem that affects an estimated 6.5 million Americans aged 20 years or older [1]. CHF is associated with frequent hospital admissions, reduced quality of life, and huge economic burden to the healthcare system [2]. There is increasing evidence that $\mathrm{CHF}$ is also related to cognitive impairment, dementia, and Alzheimer's disease [3, 4]. Conversely, cognitive impairment is associated with adverse outcomes in CHF patients, including poor self-care [5], poor medication [6] and treatment adherence [7], and high mortality [8].

Previous work has demonstrated that many medical comorbidities play an important role in the pathogenesis of cognitive impairment in $\mathrm{CHF}$ patients, including hypertension [9], type 2 diabetes mellitus [10], atrial fibrillation [11], obesity [12], chronic renal dysfunction [13], anemia [14], hyponatremia [15], depression [16], and sleep apnea [17]. However, the underlying mechanisms remain unclear.

Uric acid (UA) is the final product of purine catabolism and is excreted by the kidneys. In recent years, evidence has consistently shown that the level of serum UA is associated with cognitive function, but this relationship remains controversial. Some studies have indicated that the higher level of serum UA is associated with better cognitive performance owing to the antioxidant property of serum UA [18-23]. Specifically, a retrospective study including 1374 elderly showed that higher levels of serum UA were related to better cognitive function after controlling for cardiovascular risk factors [18]. A large cross-sectional study consisting of 10,039 Chinese community-dwelling participants aged $\geq 55$ years indicated that high serum UA was associated with a decreased risk of cognitive impairment after adjusting for age, sex, lifestyle, relevant diseases and the apolipoprotein $\mathrm{E}$ (APOE) $\varepsilon 4$ allele [19]. A prospective cohort study found that elevated serum UA predicted a decreased risk of dementia after adjusting for several cardiovascular risk factors among 4618 participants aged $\geq 55$ years and that higher serum UA at baseline predicted better cognitive performance later in life in the absence of cardiovascular risk factors among 1724 participants who remained free of dementia during follow-up [21]. Moreover, a case-control study demonstrated that serum UA levels were significantly lower in Alzheimer's disease (AD) patients compared to healthy controls [22]. In addition, a nested casecontrol study including 388 new Parkinson's disease (PD) patients (202 men and 186 women) and 1267 controls showed that higher serum UA predicted a lower risk of developing $\mathrm{PD}$ in men but not in women [23]. On the contrary, some studies have demonstrated that elevated serum UA is related to poorer cognitive function by the pro-oxidant character of serum UA [24-27]. Specifically, a cross-sectional study of 1144 participants aged $\geq 70$ years indicated that higher serum UA was associated with worse cognitive function among women but not among men, especially among women with cardiovascular disease [24]. Another study including 288 healthy young elderly from the historical cohort of the Brisighella Heart Study found a tight inverse relationship between circulating serum UA levels and cognitive performance [25]. Moreover, a population-based cohort study of 1598 healthy older people from the community demonstrated a positive association between serum UA and the risk of dementia, especially vascular or mixed dementia over 12 years of follow-up [27].

Elevated serum UA or hyperuricemia has been well demonstrated to be common in CHF patients $[28,29]$ and a marker of adverse outcomes in CHF patients, including rehospitalization, higher all-cause mortality, and higher cardiovascular mortality [29-31]. However, the specific role of serum UA in cognitive function among $\mathrm{CHF}$ populations has not been addressed. Enlightening the potential beneficial or harmful effects of serum UA on cognitive function in CHF patients may provide a better understanding of potential pathogenesis and interventions for cognitive impairment.

Moreover, previous work has indicated that serum UA may have different effect on cognitive function in men and women [20, 24, 32]. One study demonstrated that there was an inverse correlation between serum UA and the risk of cognitive impairment only in male participants [20]. Another study found that serum UA was potentially beneficial for attention/processing speed only among older men [32]. However, a cross-sectional study indicated that higher serum UA predicted worse cognitive performance in women [24]. Whereas, a sexstratified analysis on the relationship between serum UA and cognitive function in CHF patients has been not explored. Such analysis is important because elevated serum UA is more common [29, 33] and associated with poorer ejection fraction [34] in male CHF patients.

Therefore, the present study aimed to examine the independent association between serum UA and cognitive function in a sample of hospitalized patients with $\mathrm{CHF}$ and stratified by sex.

\section{Methods}

\section{Participants}

This study was a descriptive cross-sectional design. Between August 2019 and December 2019, a convenience sample of 192 patients hospitalized for symptomatic HF with reduced ejection fraction (HFrEF) or with preserved ejection fraction (HFpEF) and confirmed by the cardiologists was selected from the cardiology inpatient department of Tianjin First Central Hospital, a large (more 
than 1500 beds) and comprehensive (47 clinical professional departments) hospital in Tianjin, China.

The inclusion criteria were as follows: (1) aged 45 to 85 years at enrollment, (2) a primary diagnosis of $\mathrm{HF}$ as defined by the clinical criteria of Chinese Heart Failure Diagnosis and Treatment Guidelines (typical symptoms (e.g., dyspnea, fatigue, or decreased exercise capacity), signs (e.g., edema or rale), and chest X-ray evidence of congestion or structural and functional abnormalities on cardiac ultrasound) [35], (3) New York Heart Association (NYHA) functional class II-IV of $\geq 3$ months duration. The age range of $45-85$ years was used to maximize the number of participants with some cognitive impairment and to minimize the number of participants with dementia [36].

The exclusion criteria were as follows: (1) history of cardiac surgery within past 3 months, (2) significant neurological disorder (e.g. Alzheimer's disease, dementia, stroke, seizures, multiple sclerosis), (3) head injury with $>10$ min loss of consciousness, (4) severe psychiatric disorder (e.g. schizophrenia, bipolar disorder), (5) past or current substance abuse/dependence, (6) renal failure (estimated glomerular filtration rate $<15 \mathrm{ml} / \mathrm{min} / 1.73$ $\mathrm{m}^{2}$ ), (7) past or current uric acid medication (e.g. allopurinol, benzbromarone, febuxostat), (8) inability to answer questionnaires independently due to language barriers, or visual/hearing acuity.

\section{Measures}

\section{Cognitive function}

The Beijing version of the Montreal Cognitive Assessment (MoCA) was used to assess cognitive function. This tool has been shown to be sensitive for screening cognitive impairment in patients with HF [37]. In the instrument development study, the MoCA had high sensitivity (90\%) and specificity (78\%) for detecting mild cognitive impairment [38]. The study undertaken in Eastern China indicated that The Beijing version of MoCA had a sensitivity of $92 \%$ and a specificity of $85 \%$ for identifying mild cognitive impairment [39]. The MoCA examines eight cognitive domains, including visuospatial/executive function, naming, memory, attention, language, abstraction, delayed recall, and orientation. Total possible score ranges form 0 to 30 points, with a score below 26 indicating cognitive impairment $[37,38]$. A low educational level is corrected by adding 1 point to the total score for $\leq 12$ years of formal education [38].

\section{Serum uric acid and other biochemistry indicators}

Blood samples were collected after an overnight fasting $(\geq 8 \mathrm{~h}$ ) using standardized equipment and procedures for measuring serum UA and other biochemistry indicators (serum hemoglobin, hypersensitive $\mathrm{C}$-reactive protein and creatinine). All biochemistry analyses were performed in the central biochemistry laboratory of Tianjin First Central Hospital using standard automated procedures. We defined as hyperuricemia as serum UA $\geq 7 \mathrm{mg} / \mathrm{dl}$ $(420 \mu \mathrm{mol} / \mathrm{L})$ in men and $\geq 6 \mathrm{mg} / \mathrm{dl}(360 \mu \mathrm{mol} / \mathrm{L})$ in women [40]. The estimated glomerular filtration rate (eGFR) was calculated using the Modification of Diet in Renal Disease Study equation [41].

\section{Depressive symptoms}

The Chinese version of the Zung Self-Rating Depression Scale (SDS) was used to measure depressive symptoms. The SDS consisted of 20 items with each item rated on a four-point Likert scale ranging from 1 to 4 . The total raw score ranges from 20 to 80 , and the standard score is the integer portion of the product of 1.25 and the total raw score. According to the Chinese norm, depression is defined as the standard score $\geq 53$ [42].

\section{Demographic and medical characteristics}

Demographic and medical variables were collected through participant self-report, and supplemented and corroborated by medical record review. Through these methods, demographic (e.g. age, gender) and medical history (e.g. hypertension, diabetes, atrial fibrillation) were ascertained. The severity of HF was assessed with NYHA functional class and left ventricular ejection fraction (LVEF). Body mass index (BMI) was calculated as the ratio of weight (in kilograms) to height squared (in square meters).

\section{Procedures}

The study was in accordance with the declaration of Helsinki, and informed consent was obtained from all patients before enrolment. All study procedures were approved by The Medical Ethics Committee of Tianjin First Central Hospital. In additional to medical record review, participants completed demographic, medical and psychological self-report measures. The psychometric evaluation of the MoCA was then administered to assess visuospatial/executive function, naming, memory, attention, language, abstraction, delayed recall, and orientation. All measures were conducted in a clinical examination room within $24 \mathrm{~h}$ before discharge from the hospital. In order to improve the quality of reporting in observational studies, the present study was organized in a manner compliant with the Strengthening the Reporting of Observational Studies in Epidemiology (STROBE) statement.

\section{Statistical analyses}

The SPSS version 17.0 (SPSS Inc., Chicago, Illinois, USA) was used to perform statistical analyses. Descriptive statistics were used to illustrate the characteristics of the study participants. Normally distributed continuous variables were shown with mean \pm standard deviation $(\mathrm{SD})$, and non-normally continuous data were described 
with medians and quartiles. Categorical variables were shown with frequencies and percentages.

Independent sample $t$-test, Mann-Whitney $\mathrm{U}$ test and Pearson's chi-square test or Fisher's exact test were used to analyze the differences of the study variables between male and female CHF patients.

To explore the independent association of serum UA on cognitive function in CHF patients, a multiple linear hierarchical regression analysis was preferable to be conducted [43]. Specifically, the MoCA score was included as the dependent variable, while serum UA was included as independent variable. To control for potential confounders of cognitive function, age, gender, educational level, NYHA function class, LVEF, BMI, serum hemoglobin, hypersensitive C-reactive protein (hs-CRP), eGFR, the diagnostic history of hypertension, type 2 diabetes mellitus, and atrial fibrillation, and SDS score were included as covariates.

Following this analysis, two separate multiple linear hierarchical regression analyses were performed to determine the independent effect of serum UA on cognitive function in male and female CHF patients. Each model was examined by entering potential confounders (age, educational level, NYHA function class, LVEF, BMI, serum hemoglobin, hs-CRP, eGFR, the diagnostic history of hypertension, type 2 diabetes mellitus, and atrial fibrillation, SDS score) into block 1 and entering an independent variable (serum UA) into block 2. Change in $R^{2}$ from block 1 to block 2 determined the significance of the incremental predictive validity of serum UA over the covariates.

Sample size is calculated based on the number of independent variables included in the regression equation whereby the number of participants should be at least 510 times of the number of independent variables entered into the regression equation [44]. The numbers of independent variables were 14 in the first regression model, and 13 in the second and third regression model, thus, sample size was sufficient for the first regression model including 192 CHF patients, for the second regression model including 121 men, and for the third regression model including 71 women.

Since hs-CRP levels were not normally distributed, we used a $\log 10$ transformation for their use in the multiple linear hierarchical regression analyses. The results of multiple linear hierarchical regression analyses were presented by beta coefficients $(\beta)$ and $95 \%$ confidence intervals $(\mathrm{CI})$ for $\beta$. A $p$-value of $<0.05$ (two-sided) was considered to be statistically significant.

\section{Results}

Demographic, medical, and psychological differences between male and female CHF patients

A total of $192 \mathrm{CHF}$ patients (mean age $66.1 \pm 10.6$ years, $63.0 \%$ male) were recruited for the study. As presented in
Table 1, the current sample had a mean serum UA concentration of $7.3 \pm 2.6 \mathrm{mg} / \mathrm{dL}$. Hyperuricemia was present in $54.7 \%$ (105 of 192) of CHF patients, 52.9\% (64 of 121) of men, and $57.7 \%$ (41 of 71 ) of women.

No significant differences were determined between male and female CHF patients in terms of NYHA functional class, BMI, hs-CRP, eGFR, hyperuricemia, hypertension, type 2 diabetes mellitus, atrial fibrillation, or SDS score. However, male CHF patients were younger $(p=0.005)$, and had different educational level $(p=$ $0.000)$, lower LVEF level $(p=0.017)$, higher hemoglobin level $(p=0.000)$, and higher serum UA level $(p=0.044)$.

\section{Cognitive function}

In term of cognitive function, the mean MoCA score of the total participants was $25.1 \pm 2.9$. Based on the MoCA score, $53.6 \%$ (103 of 192) of the whole study population had cognitive impairment, including 42.1\% (51 of 121) of men and 72.3\% (52 of 71) of women. Specifically, women had lower MoCA score $(p=0.000)$, and were more likely to have cognitive impairment compared with men $(p=0.000)$ (Table 1).

\section{Serum UA is independently associated with cognitive function in CHF patients}

A multiple linear hierarchical regression analysis was conducted to determine the predictive validity of serum UA on cognitive function in CHF patients. As presented in Table 2, block 1 with demographic, medical and psychological variables was significantly associated with cognitive function $\left(R^{2}=0.584, p=0.000\right)$. Specifically, older age $(\beta=-0.353, p=0.000)$, lower educational level $(\beta=0.297, p=0.000)$, higher hs-CRP $(\beta=-0.188, p=$ $0.000)$, and higher SDS score $(\beta=-0.261, p=0.000)$ emerged as significant predictors of poorer cognitive function in CHF patients.

After adjusting for demographic, medical and psychological variables, serum UA showed significant predictive validity for cognitive function in CHF patients $(\beta=-$ 0.130, $\Delta \mathrm{R}^{2}=0.014, p=0.015$ ).

\section{Serum UA is independently associated with cognitive function in male but not in female CHF patients}

Two separate multiple linear hierarchical regression analyses controlling for demographic, medical and psychological characteristics were conducted to clarify the independent effect of serum UA on cognitive function in male and female CHF patients.

In male CHF patients, demographic, medical and psychological characteristics in block 1 made significant contributions to the prediction of cognitive function, explaining $51.9 \%$ of the variance $\left(\mathrm{R}^{2}=0.519, p=0.000\right)$. Specifically, older age $(\beta=-0.286, p=0.001)$, lower educational level $(\beta=0.287, p=0.000)$, atrial fibrillation 
Table 1 Characteristics of participants $(n=192)$

\begin{tabular}{|c|c|c|c|c|}
\hline & $\begin{array}{l}\text { Total sample } \\
(n=192)\end{array}$ & $\begin{array}{l}\text { Men } \\
(n=121)\end{array}$ & $\begin{array}{l}\text { Women } \\
(n=71)\end{array}$ & $P$-value \\
\hline \multicolumn{5}{|l|}{ Demographic characteristics } \\
\hline Age (years) & $66.1 \pm 10.6$ & $64.1 \pm 10.5$ & $69.5 \pm 9.9$ & $0.001^{a}$ \\
\hline Male & $121(63.0)$ & - & - & \\
\hline Educational level (years) & & & & $0.000^{b}$ \\
\hline $0-6$ & $53(27.6)$ & $18(14.9)$ & $35(49.3)$ & \\
\hline $7-9$ & $53(27.6)$ & 37 (30.6) & $16(22.5)$ & \\
\hline $10-12$ & $65(33.9)$ & $49(40.5)$ & $16(22.5)$ & \\
\hline$\geq 13$ & $21(10.9)$ & $17(14.0)$ & $4(5.6)$ & \\
\hline \multicolumn{5}{|c|}{ Medical and psychological characteristics } \\
\hline NYHA functional class & & & & $0.212^{b}$ \\
\hline$\|$ & $35(18.2)$ & $24(19.8)$ & $11(15.5)$ & \\
\hline III & $106(55.2)$ & $70(57.9)$ & $36(50.7)$ & \\
\hline IV & $51(26.6)$ & $27(22.3)$ & $24(33.8)$ & \\
\hline LVEF (\%) & $37.6 \pm 12.3$ & $36.0 \pm 11.8$ & $40.4 \pm 12.7$ & $0.017^{\mathrm{a}}$ \\
\hline BMI $\left(\mathrm{Kg} / \mathrm{m}^{2}\right)$ & $25.0 \pm 4.5$ & $25.2 \pm 4.1$ & $24.7 \pm 5.1$ & $0.540^{c}$ \\
\hline Hemoglobin(g/dL) & $13.0 \pm 2.4$ & $13.8 \pm 2.3$ & $11.7 \pm 2.1$ & $0.000^{\mathrm{a}}$ \\
\hline hs-CRP (mg/L) & $4.4(1.8-16.4)$ & $4.2(1.4-12.4)$ & $5.2(2.4-19.3)$ & $0.056^{d}$ \\
\hline eGFR $\left(\mathrm{ml} / \mathrm{min} / 1.73 \mathrm{~m}^{2}\right)$ & $72.8 \pm 30.8$ & $74.1 \pm 31.6$ & $70.7 \pm 29.4$ & $0.457^{\mathrm{a}}$ \\
\hline Serum UA (mg/dl) & $7.3 \pm 2.6$ & $7.6 \pm 2.6$ & $6.8 \pm 2.5$ & $0.044^{\mathrm{a}}$ \\
\hline Hyperuricemia & $105(54.7)$ & $64(52.9)$ & $41(57.7)$ & $0.514^{b}$ \\
\hline Hypertension & $128(66.7)$ & $79(65.3)$ & $49(69.0)$ & $0.597^{\mathrm{b}}$ \\
\hline Type 2 diabetes mellitus & $84(43.8)$ & $57(47.1)$ & $27(38.0)$ & $0.221^{\mathrm{b}}$ \\
\hline Atrial fibrillation & $73(38.0)$ & $47(38.8)$ & $26(36.6)$ & $0.759^{b}$ \\
\hline SDS score & $54.7 \pm 10.0$ & $53.9 \pm 10.1$ & $56.1 \pm 9.8$ & $0.147^{\mathrm{a}}$ \\
\hline \multicolumn{5}{|l|}{ Cognitive characteristics } \\
\hline MoCA score & $25.1 \pm 2.9$ & $25.8 \pm 2.7$ & $23.9 \pm 2.9$ & $0.000^{\mathrm{a}}$ \\
\hline Cognitive impairment & $103(53.6)$ & $51(42.1)$ & $52(73.2)$ & $0.000^{b}$ \\
\hline
\end{tabular}

Continuous variables represented as mean $\pm \mathrm{SD}$ and median (Q1-Q3), categorical variables as $\mathrm{n}(\%)$

NYHA New York Heart Association, LVEF left ventricular fraction, BMI body mass index, $h s$-CRP hypersensitive C-reactive protein, eGFR estimated glomerular filtration rate, UA uric acid, SDS Self-Rating Depression Scale, MoCA Montreal Cognitive Assessment

${ }^{\mathrm{a}} t$-test

'Pearson's chi-square test

't'-test

${ }^{\mathrm{d}}$ Mann-Whitney U-test

$(\beta=-0.174, p=0.029)$, and higher SDS score $(\beta=-$ 0.293, $p=0.001$ ) were associated with poorer cognitive function. After adjusting demographic, medical and psychological characteristics, serum UA significantly contributed an additional $4.9 \%$ of the variance on the prediction of cognitive function in male CHF patients $\left(\beta=-0.247, \Delta \mathrm{R}^{2}=0.049, p=0.001\right)$ (Table 3).

In female CHF patients, several demographic, medical and psychological characteristics in block 1 was significantly related to cognitive function $\left(\mathrm{R}^{2}=0.672, p=\right.$ $0.000)$, including age $(\beta=-0.479, p=0.000)$, educational level $(\beta=0.334, p=0.000)$, hs-CRP $(\beta=-0.234, p=$ $0.012)$, and depression $(\beta=-0.260, p=0.008)$. However, after controlling for demographic, medical and psychological variables, serum UA was not independently related to cognitive function $\left(\beta=-0.005, \Delta \mathrm{R}^{2}=0.000, p=\right.$ 0.955) (Table 4).

\section{Discussion}

Previous studies on the association between serum UA and cognitive function have conflicting results and no study so far has performed analyses among CHF populations. To the best of our knowledge, the current study is the first to show that elevated serum UA is independently associated with poorer performance on cognitive function in CHF patients after adjusting for demographic, medical, 
Table 2 A hierarchical regression of serum UA predicting cognitive function in patients with CHF $(n=192)$

\begin{tabular}{|c|c|c|c|c|c|c|}
\hline & \multicolumn{6}{|c|}{ Cognitive function } \\
\hline & \multirow[t]{2}{*}{$\bar{\beta}$} & \multicolumn{2}{|l|}{$95 \% \mathrm{Cl}$} & \multirow[t]{2}{*}{$R^{2}$} & \multirow[t]{2}{*}{$\Delta R^{2}$} & \multirow[t]{2}{*}{$P$-value } \\
\hline & & Lower & Upper & & & \\
\hline Block 1 & - & - & - & 0.584 & - & $0.000 * *$ \\
\hline Age & -0.353 & -0.474 & -0.231 & & & $0.000^{* *}$ \\
\hline Gender & -0.101 & -0.213 & 0.012 & & & 0.080 \\
\hline Educational level & 0.297 & 0.188 & 0.406 & & & $0.000^{* *}$ \\
\hline NYHA function class & -0.035 & -0.145 & 0.076 & & & 0.536 \\
\hline LVEF & 0.013 & -0.100 & 0.125 & & & 0.825 \\
\hline BMI & 0.070 & -0.041 & 0.180 & & & 0.214 \\
\hline Hemoglobin & -0.084 & -0.208 & 0.040 & & & 0.184 \\
\hline hs-CRP & -0.188 & -0.292 & -0.084 & & & $0.000^{* *}$ \\
\hline eGFR & -0.002 & -0.111 & 0.107 & & & 0.967 \\
\hline Hypertension & -0.073 & -0.177 & 0.032 & & & 0.171 \\
\hline Type 2 diabetes mellitus & -0.009 & -0.108 & 0.090 & & & 0.852 \\
\hline Atrial fibrillation & -0.080 & -0.190 & 0.030 & & & 0.154 \\
\hline SDS score & -0.261 & -0.379 & -0.142 & & & $0.000^{* *}$ \\
\hline Block 2 & - & - & - & 0.598 & 0.014 & $0.015^{*}$ \\
\hline Serum UA & -0.130 & -0.235 & -0.025 & & & 0.015 \\
\hline
\end{tabular}

UA uric acid, CHF chronic heart failure, NYHA New York Heart Association, LVEF left ventricular fraction, BMI body mass index, hs-CRP hypersensitive C-reactive protein, GFR estimated glomerular filtration rate, SDS self-rating depression scale

$\beta$ standardized coefficients, $\mathrm{Cl}$ confidence interval

${ }^{*} P<0.05 ;{ }^{*} P<0.01$

Table 3 A hierarchical regression of serum UA predicting cognitive function in male CHF patients $(n=121)$

\begin{tabular}{|c|c|c|c|c|c|c|}
\hline & \multicolumn{6}{|c|}{ Cognitive function } \\
\hline & \multirow[t]{2}{*}{$\bar{\beta}$} & \multicolumn{2}{|l|}{$95 \% \mathrm{Cl}$} & \multirow[t]{2}{*}{$R^{2}$} & \multirow[t]{2}{*}{$\Delta R^{2}$} & \multirow[t]{2}{*}{$P$-value } \\
\hline & & Lower & Upper & & & \\
\hline Block 1 & - & - & - & 0.519 & - & $0.000^{* * *}$ \\
\hline Age & -0.286 & -0.453 & -0.119 & & & $0.001^{* *}$ \\
\hline Educational level & 0.287 & 0.142 & 0.432 & & & $0.000^{* *}$ \\
\hline NYHA function class & -0.051 & -0.201 & 0.099 & & & 0.501 \\
\hline LVEF & -0.080 & -0.235 & 0.074 & & & 0.304 \\
\hline $\mathrm{BMI}$ & 0.074 & -0.081 & 0.229 & & & 0.344 \\
\hline Hemoglobin & -0.098 & -0.259 & 0.062 & & & 0.228 \\
\hline hs-CRP & -0.140 & -0.282 & 0.003 & & & 0.054 \\
\hline eGFR & 0.028 & -0.122 & 0.179 & & & 0.712 \\
\hline Hypertension & -0.046 & -0.188 & 0.097 & & & 0.528 \\
\hline Type 2 diabetes mellitus & 0.026 & -0.112 & 0.165 & & & 0.710 \\
\hline Atrial fibrillation & -0.174 & -0.329 & -0.019 & & & $0.029^{*}$ \\
\hline SDS score & -0.293 & -0.459 & -0.126 & & & $0.001^{* *}$ \\
\hline Block 2 & - & - & - & 0.568 & 0.049 & $0.001^{* *}$ \\
\hline Serum UA & -0.247 & -0.388 & -0.106 & & & $0.001^{* *}$ \\
\hline
\end{tabular}

UA uric acid, CHF chronic heart failure, NYHA New York Heart Association, LVEF left ventricular fraction, BMI body mass index, hs-CRP hypersensitive C-reactive protein, eGFR estimated glomerular filtration rate, SDS self-rating depression scale $\beta$ standardized coefficients, $\mathrm{Cl}$ confidence interval

${ }^{*} P<0.05$; ** $P<0.01$ 
Table 4 A hierarchical regression of serum UA predicting cognitive function in female CHF patients $(n=71)$

\begin{tabular}{|c|c|c|c|c|c|c|}
\hline & \multicolumn{6}{|c|}{ Cognitive function } \\
\hline & \multirow[t]{2}{*}{$\beta$} & \multicolumn{2}{|l|}{$95 \% \mathrm{Cl}$} & \multirow[t]{2}{*}{$R^{2}$} & \multirow[t]{2}{*}{$\Delta R^{2}$} & \multirow[t]{2}{*}{$P$-value } \\
\hline & & Lower & Upper & & & \\
\hline Block 1 & - & - & - & 0.672 & - & $0.000^{*-}$ \\
\hline Age & -0.479 & -0.677 & -0.282 & & & $0.000^{* *}$ \\
\hline Educational level & 0.334 & 0.173 & 0.495 & & & $0.000^{* *}$ \\
\hline NYHA function class & -0.026 & -0.209 & 0.157 & & & 0.774 \\
\hline LVEF & 0.140 & -0.041 & 0.320 & & & 0.128 \\
\hline $\mathrm{BMI}$ & 0.073 & -0.111 & 0.257 & & & 0.430 \\
\hline Hemoglobin & 0.005 & -0.184 & 0.193 & & & 0.961 \\
\hline hs-CRP & -0.234 & -0.415 & -0.053 & & & $0.012^{*}$ \\
\hline eGFR & -0.128 & -0.317 & 0.062 & & & 0.183 \\
\hline Hypertension & -0.115 & -0.291 & 0.061 & & & 0.195 \\
\hline Type 2 diabetes mellitus & 0.008 & -0.164 & 0.180 & & & 0.925 \\
\hline Atrial fibrillation & 0.033 & -0.142 & 0.208 & & & 0.704 \\
\hline SDS score & -0.260 & -0.451 & -0.070 & & & $0.008^{* *}$ \\
\hline Block 2 & - & - & - & 0.672 & 0.000 & 0.955 \\
\hline Serum UA & -0.005 & -0.185 & 0.175 & & & 0.955 \\
\hline
\end{tabular}

UA uric acid, CHF chronic heart failure, NYHA New York Heart Association, LVEF left ventricular fraction, BMI body mass index, hs-CRP hypersensitive C-reactive protein, eGFR estimated glomerular filtration rate, SDS self-rating depression scale

$\beta$ standardized coefficients, $\mathrm{Cl}$ confidence interval

* $P<0.05$; * $P<0.01$

and psychological characteristics. Furthermore, another new finding of the present study is that elevated serum UA is independently associated with poorer performance on cognitive function in male CHF patients but not in female CHF patients.

In recent years, there is increasing evidence that serum UA may prevent the decline of cognitive function owing to its antioxidant efficacy or may worsen cognitive function by gaining pro-oxidant character. As the consequence, the association between serum UA and cognitive function remains controversial. Our study is consistent with several previous studies-mainly from elderly-showing that high serum UA is related to an increased risk of cognitive impairment. Indeed, a crosssectional study including 1016 community-dwelling older persons demonstrated that high serum UA predicted an increased risk to suffer from a dementia syndrome [45]. Similarly, a population-based cohort study of 3720 healthy Urban persons aged 30-64y indicated that a higher baseline serum UA predicted poorer cognitive function over-time in the area of visual memory/ visuo-construction [32]. Furthermore, Afsar et al. showed that serum UA was independently and inversely associated with cognitive function in patients with chronic kidney disease [46]. Additionally, a metaanalysis of 11 case-control studies found that there was no difference on the levels of serum UA between AD patients and healthy controls, but that serum UA might decrease in $\mathrm{AD}$ patients after an appropriate interpretation [47]. In the light of these studies, it can be said that the antioxidant properties of UA are replaced by strong pro-oxidant effects for higher circulating concentrations of serum UA [48], which may be potentially associated with structural and functional brain changes [49].

However, several studies have reported results in contrast to our current study. Some cross-sectional studies have suggested that higher uric acid levels are a protective factor for cognitive impairment in the elderly $[19,50$, 51]. Moreover, serum UA levels have been found to be low in subjects with established $\mathrm{AD}$ or vascular cognitive impairment $[52,53]$. In addition, Huang et al. found that increased serum UA was related to a decreased risk of MCI among T2DM patients whose serum UA level was below the cut-point $(388.63 \mu \mathrm{mol} / \mathrm{L})$ [54]. Furthermore, Some case-control studies have demonstrated that higher serum UA levels are linked to a decreased risk of cognitive impairment in the elderly $[22,55,56]$. Specifically, Al-khateeb et al. found that serum UA levels were significantly lower in $\mathrm{AD}$ patients compared to healthy controls [22]. A random sampling study including 58 patients with mild cognitive impairment (MCI) and 57 healthy elderly indicated that a high uric acid level was associated with a lower risk for MCI [55]. Wang et al. suggested that hyperuricemia was a protective factor for mild cognitive impairment (MCI) in non-obese elderly [56]. In addition, some prospective cohort studies have 
indicated that increased baseline serum UA level is associated with subsequently improved cognitive performances in patients with preexisting cardiovascular disease [57] and PD [58]. Furthermore, a meta-analysis including 21 case-control and 3 cohort studies indicated that higher serum UA level is a protective factor of $\mathrm{AD}$ [59]. These findings question the hypothesis that circulating serum UA levels may potentially involve in the pathophysiology of cognitive impairment, and further longitudinal studies are needed to corroborate such results.

Although the exact mechanisms accounting for abovementioned apparent paradox are unclear, many factors play an important role in the controversial results, including sample sizes, dementia groups (such as AD, PD, and vascular dementia), age, and cardiovascular risk factors [60]. In CHF populations, several potential mechanisms may explain the inverse and independent association between serum UA and cognitive function. One potential explanation is the presence of white matter lesions because of high circulating concentrations of serum UA. This hypothesis is supported by the Rotterdam Scan Study which reported that elevated serum UA was related to white matter atrophy and worse cognition [61]. Another study also suggested that higher serum UA remained to be associated with greater white matter hyperintensities after adjusting for age, sex, race, education, hypertension, diabetes, alcohol abuse, smoking, and body mass [49]. Another possible mechanism may be the generation of inflammation induced by serum UA, as evidence shows that serum UA contributes to inflammatory markers [62] and ultimately result in cognitive dysfunction [63]. In addition, oxidative stress may be implicated, because serum UA has be shown to induce oxidative stress, which has been reported to increase the risk of endothelial dysfunction $[48,64]$ and result in cognitive impairment [65]. Furthermore, elevated serum UA levels are associated with an increased risk for vascular disease, such as hypertension, diabetes and chronic kidney disease $[66,67]$, which in turn contribute to vascular cognitive impairment [68]. Future studies are needed to explain the specific mechanisms by which serum UA contributes to cognitive impairment above and beyond HF-related pathology.

In addition, our results indicated an inverse association between serum UA and cognitive function only in male CHF patients, which is in contrast with the results form a study in which an inverse association between serum UA and cognitive function only among women, especially with cardiovascular diseases [24]. A possible explanation for the discrepancy could be the different characteristics of participants and instruments used to measure cognitive function, and further longitudinal studies are needed to corroborate such results. The exact mechanisms by which serum UA is independently associated with worse cognitive function in male CHF patients are unclear, but one potential explanation is that higher serum UA may result in lower cardiac output and ultimately result in lower cerebral blood flow in male CHF patients. Evidence shows that serum UA is negatively associated with LVEF in male CHF patients but not in female CHF patients [34]. In the present study, male CHF patients had higher serum UA than female CHF patients. Similarly, Hamaguchi et al. [29] and Vaduganathan et al. [33] also found that serum UA was commonly elevated in male CHF patients. Therefore, male CHF patients may have lower cardiac output because of higher serum UA levels, which may ultimately result in lower cerebral blood flow.

\section{Limitations}

Our study had several limitations. First, the present study was a cross-sectional design; thus, whether serum UA was the cause or consequence of cognitive function in CHF population can not be ascertained in the present design. Second, selecting participants by convenience sampling methods might limit the generalizability of our findings, and probability sampling techniques are recommended for future studies to increase the representativeness of the sample. Additionally, the MoCA is not the gold standard for measuring cognitive function; however, there is increasing evidence that the MoCA is a more comprehensive and suitable tool for screening cognitive impairment in HF patients. Although not designed specifically for the HF population, the MoCA is the only instrument that includes domain subscales and tests all of which most often affected in HF [37]. In addition, the number of CHF patients in the current study was relatively small, and future studies examining the associations between serum UA and cognitive function in CHF patients should employ more samples to increase the validity of our findings. Moreover, some potential confounding variables (e.g., dietary habits [25], systolic blood pressure [69], diuretics, beta-blockers, angiotensin-converting enzyme (ACE) inhibitors, angiotensin II receptor blockers, insulin) were not collected in our study, and future studies should assess more potential variables that may affect the relationship between serum UA and cognitive function in CHF patients. Patients with a history of stroke were excluded, but subtle and silent cerebrovascular disease could not be fully ruled out.

\section{Conclusions}

In conclusion, our cross-sectional study demonstrates that higher levels of serum UA are independently associated with poorer cognitive function in $\mathrm{CHF}$ patients after controlling for demographic, medical, and psychological characteristics. Furthermore, elevated serum UA 
is independently associated with poorer performance on cognitive function in male CHF patients. These findings provide evidence to reevaluate the clinical strategies of reducing serum UA in CHF populations, especially in male CHF populations. Longitudinal studies are strongly warranted to explore whether elevated serum UA increases the risk of cognitive decline in CHF populations and stratified by sex.

\section{Abbreviations \\ CHF: Chronic heart failure; UA: Uric acid; HFrEF: HF with reduced ejection fraction; HFpEF: HF with preserved ejection fraction; NYHA: New York heart association; MoCA: Montreal cognitive assessment; SDS: Zung self-rating depression scale; LVEF: Left ventricular ejection fraction; BMI: Body mass index; STROBE: Strengthening the reporting of observational studies in epidemiology; hs-CRP: C-reactive protein}

\section{Acknowledgments}

The authors thank all doctors and nurses at the Department of Cardiology in the Tianjin First Central Hospital, China for their help with recruitment and data collection, and this research received no specific grant from any funding agency in the public, commercial, or not-for-profit sectors.

\section{Authors' contributions}

(1) Study design: WN, HY and CL. (2) Data collection: WN. (3) Data analysis: WN and HY. (4) Manuscript writing: WN and HY. (5) Final approval of the manuscript: CL. All authors have read and approved the manuscript.

\section{Funding}

This research received no specific grant from any funding agency in the public, commercial, or not-for-profit sectors.

\section{Availability of data and materials}

All data analysed during this study are included in this published article and its supplementary information files.

\section{Ethics approval and consent to participate}

This study complies with the Declaration of Helsinki. The Medical Ethics Committee of Tianjin First Central Hospital approved the study procedures and all participants provided written informed consent prior to study enrollment.

\section{Consent for publication}

Not applicable.

\section{Competing interests}

The authors have no conflicts of interest to declare.

\section{Author details}

${ }^{1}$ First Center Clinic College of Tianjin Medical University, Tianjin First Central Hospital, No 24 Fukang Road, Nankai District, Tianjin 300192, China. ${ }^{2}$ Department of Cardiology, Tianjin First Central Hospital, No 24 Fukang Road, Nankai District, Tianjin 300192, China. ${ }^{3}$ School of Nursing, Tianjin University of Traditional Chinese Medicine, No 10 Panyang Road, West District, Tuanbo New Town, Jinghai District, Tianjin 301617, China.

Received: 13 May 2020 Accepted: 10 August 2020

Published online: 20 August 2020

\section{References}

1. Benjamin EJ, Blaha MJ, Chiuve SE, Cushman M, Das SR, Deo R, de Ferranti SD, Floyd J, Fornage M, Gillespie C, Isasi CR, Jiménez MC, Jordan LC, Judd SE, Lackland D, Lichtman JH, Lisabeth L, Liu S, Longenecker CT, Mackey RH, Matsushita K, Mozaffarian D, Mussolino ME, Nasir K, Neumar RW, Palaniappan L, Pandey DK, Thiagarajan RR, Reeves MJ, Ritchey M, Rodriguez CJ, Roth GA, Rosamond WD, Sasson C, Towfighi A, Tsao CW, Turner MB, Virani SS, Voeks JH, Willey JZ, Wilkins JT, Wu JH, Alger HM, Wong SS, Muntner P, American Heart Association Statistics Committee and Stroke Statistics Subcommittee. Heart
Disease and Stroke Statistics-2017 Update: A Report From the American Heart Association. Circulation. 2017;135:e146-603.

2. Heidenreich PA, Albert NM, Allen LA, Bluemke DA, Butler J, Fonarow GC, Ikonomidis JS, Khavjou O, Konstam MA, Maddox TM, Nichol G, Pham M, Piña IL, Trogdon JG; American Heart Association Advocacy Coordinating Committee; Council on Arteriosclerosis, Thrombosis and Vascular Biology; Council on Cardiovascular Radiology and Intervention; Council on Clinical Cardiology; Council on Epidemiology and Prevention; Stroke Council. Forecasting the impact of heart failure in the United States: a policy statement from the American Heart Association. Circ Heart Fail. 2013:6:606-619.

3. Qiu C, Winblad B, Marengoni A, Klarin I, Fastbom J, Fratiglioni L. Heart failure and risk of dementia and Alzheimer disease: a population-based cohort study. Arch Intern Med. 2006;166:1003-8.

4. Gure TR, Blaum CS, Giordani B, Koelling TM, Galecki A, Pressler SJ, Hummel SL, Langa KM. Prevalence of cognitive impairment in older adults with heart failure. J Am Geriatr Soc. 2012;60:1724-9.

5. Hjelm CM, Brostrom A, Riegel B, Årestedt K, Strömberg A. The association between cognitive function and self-care in patients with chronic heart failure. Heart Lung. 2015;44:113-9.

6. Dolansky MA, Hawkins MAW, Schaefer JT, Sattar A, Gunstad J, Redle JD, Josephson R, Moore SM, Hughes JW. Association between poorer cognitive function and reduced objectively monitored medication adherence in patients with heart failure. Circ Heart Fail. 2016;9.

7. Alosco ML, Spitznagel MB, van Dulmen M, Raz N, Cohen R, Sweet LH, Colbert LH, Josephson R, Hughes J, Rosneck J, Gunstad J. Cognitive function and treatment adherence in older adults with heart failure. Psychosom Med. 2012;74:965-73.

8. Pressler SJ, Kim J, Riley P, Gradus-Pizlo I. Memory dysfunction, psychomotor slowing, and decreased executive function predict mortality in patients with heart failure and low ejection fraction. J Card Fail. 2010;16:750-60.

9. Alosco ML, Brickman AM, Spitznagel MB, van Dulmen M, Raz N, Cohen R, Sweet LH, Colbert LH, Josephson R, Hughes J, Rosneck J, Gunstad J. The independent association of hypertension with cognitive function among older adults with heart failure. J Neurol Sci. 2012;323:216-20.

10. Alosco ML, Spitznagel MB, van Dulmen M, Raz N, Cohen $R$, Sweet $L H$, Colbert LH, Josephson R, Hughes J, Rosneck J, Gunstad J. The additive effects of type-2 diabetes on cognitive function in older adults with heart failure. Cardiol Res Pract. 2012;2012:348054.

11. Yang $H$, Niu W, Zang $X$, Lin M, Zhao $Y$. The association between atrial fibrillation and cognitive function in patients with heart failure. Eur J Cardiovasc Nurs. 2017;16:104-12.

12. Alosco ML, Spitznagel MB, Cohen R, Sweet LH, Josephson R, Hughes J, Rosneck J, Gunstad J. Obesity and cognitive dysfunction in heart failure: the role of hypertension, type 2 diabetes, and physical fitness. Eur J Cardiovasc Nurs. 2015;14:334-41.

13. Pulignano G, Del SD, Di Lenarda A, Tinti MD, Tarantini L, Cioffi G, Tolone S, Pero G, Minardi $G$. Chronic renal dysfunction and anaemia are associated with cognitive impairment in older patients with heart failure. J Cardiovasc Med (Hagerstown). 2014;15:481-90.

14. Taraghi Z, Akbari Kamrani A, Foroughan M, Yazdani J, Mahdavi A, Baghernejad SK. Cognitive impairment among elderly patients with chronic heart failure and related factors. Iran J Psychiatry Behav Sci. 2016;10:e4500.

15. Albabtain M, Brenner MJ, Nicklas JM, Hummel SL, McCormick MP, Pawlowski $J L$, Remington TL, Gure TR, Dorsch MP, Bleske BE. Hyponatremia, Cognitive Function, and Mobility in an Outpatient Heart Failure Population. Med Sci Monit. 2016:22:4978-85.

16. Hawkins MA, Dolansky MA, Schaefer JT, Fulcher MJ, Gunstad J, Redle JD, Josephson R, Hughes JW. Cognitive function in heart failure is associated with nonsomatic symptoms of depression but not somatic symptoms. J Cardiovasc Nurs. 2015;30:E9-E17.

17. Knecht KM, Alosco ML, Spitznagel MB, Cohen R, Raz N, Sweet L, Colbert LH, Josephson R, Hughes J, Rosneck J, Gunstad J. Sleep apnea and cognitive function in heart failure. Cardiovasc Psychiatry Neurol. 2012;2012:402079.

18. Tuven B, Soysal P, Unutmaz G, Kaya D, Isik AT. Uric acid may be protective against cognitive impairment in older adults, but only in those without cardiovascular risk factors. Exp Gerontol. 2017:89:15-9.

19. Xiu S, Zheng Z, Guan S, Zhang J, Ma J, Chan P. Serum uric acid and impaired cognitive function in community-dwelling elderly in Beijing. Neurosci Lett. 2017;637:182-7. 
20. Li J, Dong B, Lin P, Zhang J, Liu GJ. Association of cognitive function with serum uric acid level among Chinese nonagenarians and centenarians. Exp Gerontol. 2010;45:331-5.

21. Euser SM, Hofman A, Westendorp RG, Breteler MM. Serum uric acid and cognitive function and dementia. Brain. 2009;132:377-82.

22. Al-khateeb E, Althaher A, Al-khateeb M, Al-Musawi H, Azzouqah O, AlShweiki S, Shafagoj Y. Relation between uric acid and Alzheimer's disease in elderly Jordanians. J Alzheimers Dis. 2015;44:859-65.

23. Gao X, O'Reilly EJ, Schwarzschild MA, Ascherio A. Prospective study of plasma urate and risk of Parkinson disease in men and women. Neurology. 2016;86:520-6.

24. Perna L, Mons U, Schöttker B, Brenner $\mathrm{H}$. Association of cognitive function and serum uric acid: are cardiovascular diseases a mediator among women? Exp Gerontol. 2016;81:37-41.

25. Cicero AFG, Desideri G, Grossi G, Urso R, Rosticci M, D'Addato S, Borghi C. Brisighella Heart Study Group Serum uric acid and impaired cognitive function in a cohort of healthy young elderly: data from the Brisighella Study. Intern Emerg Med 2015;10:25-31

26. Vannorsdall TD, Kueider AM, Carlson MC, Schretlen DJ. Higher baseline serum uric acid is associated with poorer cognition but not rates of cognitive decline in women. Exp Gerontol. 2014;60:136-9.

27. Latourte A, Soumare A, Bardin T, Perez-Ruiz F, Debette S, Richette P. Uric acid and incident dementia over 12 years of follow-up: a population-based cohort study. Ann Rheum Dis. 2018;77:328-35.

28. Khan A, Shah MH, Khan S, Shamim U, Arshad S. Serum uric acid level in the severity of congestive heart failure (CHF). Pak J Med Sci. 2017;33:330-4.

29. Hamaguchi S, Furumoto T, Tsuchihashi-Makaya M, Goto K, Goto D, Yokota T, Kinugawa S, Yokoshiki H, Takeshita A, Tsutsui H. JCARE-CARD Investigators. Hyperuricemia predicts adverse outcomes in patients with heart failure. Int J Cardiol. 2011:151:143-7.

30. Shimizu T, Yoshihisa A, Kanno Y, Takiguchi M, Sato A, Miura S, Nakamura Y, Yamauchi H, Owada T, Abe S, Sato T, Suzuki S, Oikawa M, Yamaki T, Sugimoto K, Kunii H, Nakazato K, Suzuki H, Saitoh S, Takeishi Y. Relationship of hyperuricemia with mortality in heart failure patients with preserved ejection fraction. Am J Physiol Heart Circ Physiol. 2015;309:H1123-9.

31. Huang $H$, Huang $B$, Li Y, Huang $Y$, Li J, Yao H, Jing $X$, Chen J, Wang J. Uric acid and risk of heart failure: a systematic review and meta-analysis. Eur J Heart Fail. 2014:16:15-24

32. Beydoun MA, Canas JA, Dore GA, Beydoun HA, Rostant OS, FanelliKuczmarski MT, Evans MK, Zonderman AB. Serum uric acid and its association with longitudinal cognitive change among urban adults. J Alzheimers Dis. 2016:52:1415-30.

33. Vaduganathan M, Greene SJ, Ambrosy AP, Mentz RJ, Subacius HP, Chioncel O, Maggioni AP, Swedberg K, Zannad F, Konstam MA, Senni M, Givertz MM, Butler J, Gheorghiade M. Relation of serum uric acid levels and outcomes among patients hospitalized for worsening heart failure with reduced ejection fraction (from the efficacy of vasopressin antagonism in heart failure outcome study with tolvaptan trial). Am J Cardiol. 2014;114:1713-21.

34. Borghi C, Cosentino ER, Rinaldi ER, Cicero AFG. Uricaemia and ejection fraction in elderly heart failure outpatients. Eur J Clin Investig. 2014;44:573-8.

35. Chinese Medical Society of Cardiology, Chinese Journal of Cardiology Editorial Board. Chinese guidelines for the diagnosis and treatment of heart failure 2018. Zhonghua Xin Xue Guan Bing Za Zhi 2018,46(10):760-789.

36. Hawkins MA, Gathright EC, Gunstad J, Dolansky MA, Redle JD, Josephson R, Moore SM, Hughes JW. The MoCA and MMSE as screeners for cognitive impairment in a heart failure population: a study with comprehensive neuropsychological testing. Heart Lung. 2014;43:462-8.

37. Davis KK, Allen JK. Identifying cognitive impairment in heart failure: a review of screening measures. Heart Lung. 2013:42:92-7.

38. Nasreddine ZS, Phillips NA, Bedirian V, Charbonneau S, Whitehead V, Collin I, Cummings $\mathrm{J}$, Chertkow $\mathrm{H}$. The Montreal cognitive assessment, MoCA: a brief screening tool for mild cognitive impairment. J Am Geriatr Soc. 2005:53:695-9.

39. Hu JB, Zhou WH, Hu SH, Huang ML, Wei N, Qi HL, Huang JW, Xu Y. Crosscultural difference and validation of the Chinese version of Montreal Cognitive Assessment in older adults residing in Eastern China: preliminary findings. Arch Gerontol Geriatr. 2013;56:38-43.

40. Palazzuoli A, Ruocco G, De Vivo O, Nuti R, McCullough PA. Prevalence of Hyperuricemia in patients with acute heart failure with either reduced or preserved ejection fraction. Am J Cardiol. 2017;120:1146-50.

41. Levey AS, Coresh J, Greene T, Stevens LA, Zhang Y, Hendriksen S, Kusek JW, Van Lente F. Using standardized serum creatinine values in the modification of diet in renal disease study equation for estimating glomerular filtration rate. Ann Intern Med. 2006:145:247-54.

42. Lei M, Li C, Xiao X, Qiu J, Dai Y, Zhang Q. Evaluation of the psychometric properties of the Chinese version of the resilience scale in Wenchuan earthquake survivors. Compr Psychiatry. 2012;53:616-22.

43. Currie K, Rideout A, Lindsay G, Harkness K. The association between mild cognitive impairment and self-care in adults with chronic heart failure: a systematic review and narrative synthesis. J Cardiovasc Nurs. 2015;30:382-93.

44. Norman G, Streiner D. Biostatistics: the bare essentials. 3rd ed. Hamilton: Decker Inc.; 2008.

45. Ruggiero C, Cherubini A, Lauretani F, Bandinelli S, Maggio M, Di lorio A Zuliani G, Dragonas C, Senin U, Ferrucci L. Uric acid and dementia in community-dwelling older persons. Dement Geriatr Cogn Disord. 2009;27: 382-9.

46. Afsar B, Elsurer R, Covic A, Ohnson RJ, Kanbay M. Relationship between uric acid and subtle cognitive dysfunction in chronic kidney disease. Am J Nephrol. 2011;34:49-54.

47. Chen X, Guo X, Huang R, Chen Y, Zheng Z, Shang H. Serum uric acid levels in patients with Alzheimer's disease: A meta-analysis. PLoS One. 2014;9: e94084.

48. Yu MA, Sanchez-Lozada LG, Johnson RJ, Kang DH. Oxidative stress with an activation of the renin-angiotensin system in human vascular endothelial cells as a novel mechanism of uric acid-induced endothelial dysfunction. J Hypertens. 2010;28:1234-42.

49. Vannorsdall TD, Jinnah HA, Gordon B, Kraut M, Schretlen DJ. Cerebral ischemia mediates the effect of serum uric acid on cognitive function. Stroke. 2008:39:3418-20.

50. Liu M, Wang J, Zeng J, He Y. Relationship between serum uric acid level and mild cognitive impairment in Chinese community elderly. BMC Neurol. 2017:17:146

51. Wu Y, Zhang D, Pang Z, Jiang W, Wang S, Tan Q. Association of serum uric acid level with muscle strength and cognitive function among Chinese aged 50-74 years. Geriatr Gerontol Int. 2013;13:672-7.

52. Kim TS, Pae CU, Yoon SJ, Jang WY, Lee NJ, Kim JJ, Lee SJ, Lee C, Paik IH, Lee C. Decreased plasma antioxidants in patients with Alzheimer's disease. Int J Geriatr Psychiatry. 2006;21:344-8.

53. Polidori MC, Mattioli $P$, Aldred S, Cecchetti R, Stahl W, Griffiths H, Senin $U$, Sies $H$, Mecocci P. Plasma antioxidant status, immunoglobulin $g$ oxidation and lipid peroxidation in demented patients: relevance to Alzheimer disease and vascular dementia. Dement Geriatr Cogn Disord. 2004;18:265-70.

54. Huang R, Tian S, Han J, Lin H, Guo D, Wang J, An K, Wang S. U-Shaped Association Between Serum Uric Acid Levels and Cognitive Functions in Patients with Type 2 Diabetes: A Cross-Sectional Study. J Alzheimers Dis. 2009;69:135-44.

55. Xue L, Liu $Y$, Xue $H$, Xue J, Sun $K$, Wu L, Hou P. Low uric acid is a risk factor in mild cognitive impairment. Neuropsychiatr Dis Treat. 2017;13:2363-7.

56. Wang F, Zhao M, Han Z, Li D, Zhang S, Zhang Y, Kong X, Sun N, Zhang Q, Lei $P$. Hyperuricemia as a protective factor for mild cognitive impairment in non-obese elderly. Tohoku J Exp Med. 2017;242:37-42.

57. Molshatzki N, Weinstein G, Streifler JY, Goldbourt U, Tanne D Serum uric acid and subsequent cognitive performance in patients with pre-existing cardiovascular disease PLoS One 2015;10:e0120862.

58. Pellecchia MT, Savastano R, Moccia M, Picillo M, Siano P, Erro R, Vallelunga A, Amboni M, Vitale C, Santangelo G, Barone P. Lower serum uric acid is associated with mild cognitive impairment in early Parkinson's disease: a 4year follow-up study. J Neural Transm. 2016;123:1399-402.

59. Du N, Xu D, Hou X, Song X, Liu C, Chen Y, Wang Y, Li X. Inverse association between serum uric acid levels and Alzheimer's disease risk. Mol Neurobiol. 2016:53:2594-9.

60. Khan AA, Quinn TJ, Hewitt J, Fan Y, Dawson J. Serumuric acid level and association with cognitive impairment and dementia: Systematic review and meta-analysis. Age (Dordr). 2016;38:16.

61. Verhaaren BF, Vernooij MW, Dehghan A, Vrooman HA, de Boer R, Hofman A Witteman JC, Niessen WJ, Breteler MM, van der Lugt A, Ikram MA. The relation of uric acid to brain atrophy and cognition: the Rotterdam scan study. Neuroepidemiology. 2013;41:29-34.

62. Ruggiero C, Cherubini A, Ble A, Bos AJ, Maggio M, Dixit VD, Lauretani F, Bandinelli S, Senin U, Ferrucci L. Uric acid and inflammatory markers. Eur Heart J. 2006;27:1174-81. 
63. Shao X, Lu W, Gao F, Li D, Hu J, Li Y, Zuo Z, Jie H, Zhao Y, Cen X. Uric acid induces cognitive dysfunction through hippocampal inflammation in rodents and humans. J Neurosci. 2016;36:10990-1005.

64. Doehner W, Schoene N, Rauchhaus M, Leyva-Leon F, Pavitt DV, Reaveley DA, Schuler G, Coats AJ, Anker SD, Hambrecht R. Effects of xanthine oxidase inhibition with allopurinol on endothelial function and peripheral blood flow in hyperuricemic patients with chronic heart failure: results from 2 placebo-controlled studies. Circulation. 2002;105:2619-24.

65. Nunomura A, Moreira PI, Castellani RJ, Lee HG, Zhu X, Smith MA, Perry G. Oxidative damage to RNA in aging and neurodegenerative disorders. Neurotox Res. 2012;22:231-48.

66. van der Schaft N, Brahimaj A, Wen KX, Franco OH. Dehghan. The association between serum uric acid and the incidence of prediabetes and type 2 diabetes mellitus: the Rotterdam study. PLoS One. 2017;12:e179482.

67. Grayson PC, Kim SY, LaValley M, LaValley M, Choi HK. Hyperuricemia and incident hypertension: a systematic review and meta-analysis. Arthritis Care Res (Hoboken). 2011;63:102-10.

68. Gorelick PB, Scuteri A, Black SE, Decarli C, Greenberg SM, ladecola C, Launer L, Laurent S, Lopez OL, Nyenhuis D, Petersen RC, Schneider JA, Tzourio C, Arnett DK, Bennett DA, Chui HC, Higashida RT, Lindquist R, Nilsson PM, Roman GC, Sellke FW, Seshadri S, American Heart Association Stroke Council, Council on Epidemiology and Prevention, Council on Cardiovascular Nursing, Council on Cardiovascular Radiology and Intervention, and Council on Cardiovascular Surgery and Anesthesia. Vascular Contributions to Cognitive Impairment and Dementia: A Statement for Healthcare Professionals From the American Heart Association/American Stroke Association. Stroke. 2011;42:2672-713.

69. Coma Maria, González-Moneo MJ, Enjuanes C, Velázquez PP, Espargaró DB, Pérez BA, Tajes M, Garcia-Elias a, Farré N, Sánchez-Benavides G, Martí-Almor J, Comin-Colet J, Benito B. Effect of permanent atrial fibrillation on cognitive function in patients with chronic heart failure. Am J Cardiol 2016;1 17:233-239.

\section{Publisher's Note}

Springer Nature remains neutral with regard to jurisdictional claims in published maps and institutional affiliations.

Ready to submit your research? Choose BMC and benefit from:

- fast, convenient online submission

- thorough peer review by experienced researchers in your field

- rapid publication on acceptance

- support for research data, including large and complex data types

- gold Open Access which fosters wider collaboration and increased citations

- maximum visibility for your research: over $100 \mathrm{M}$ website views per year

At $\mathrm{BMC}$, research is always in progress.

Learn more biomedcentral.com/submissions 